\title{
Testosterone-induced increase in libido in a patient with a loss-of-function mutation in the $A R$ gene
}

\author{
Laura Marino1,*, Andrea Messina1,*, James S Acierno Jr¹, Franziska Phan-Hug1, Nicolas J Niederländer1, \\ Federico Santoni1, Stefano La Rosa² and Nelly Pitteloud1
}

1Department of Service of Endocrinology, Diabetes, and Metabolism, Faculty of Biology and Medicine, University of Lausanne, Lausanne University Hospital, Lausanne, Vaud, Switzerland and 2Department of Laboratory Medicine and Pathology, Centre Hospitalier Universitaire Vaudois, Lausanne, Vaud, Switzerland

*(L Marino and A Messina contributed equally to this work)

Correspondence should be addressed to $\mathrm{N}$ Pitteloud

E-mail

nelly.pitteloud@chuv.ch

\section{Summary}

Complete androgen-insensitivity syndrome (CAIS), a disorder of sex development (46,XY DSD), is caused primarily by mutations in the androgen receptor (AR). Gonadectomy is recommended due to the increased risk of gonadoblastoma, however, surgical intervention is often followed by loss of libido. We present a 26-year-old patient with CAIS who underwent gonadectomy followed by a significant decrease in libido, which was improved with testosterone treatment but not with estradiol. Genetic testing was performed and followed by molecular characterization. We found that this patient carried a previously unidentified start loss mutation in the androgen receptor. This variant resulted in an $\mathrm{N}$-terminal truncated protein with an intact DNA binding domain and was confirmed to be loss-of-function in vitro. This unique CAIS case and detailed functional studies raise intriguing questions regarding the relative roles of testosterone and estrogen in libido, and in particular, the potential non-genomic actions of androgens.

\section{Learning points}

- $\quad \mathrm{N}$-terminal truncation of androgen receptor can cause androgen-insensitivity syndrome.

- Surgical removal of testosterone-producing gonads can result in loss of libido.

- Libido may be improved with testosterone treatment but not with estradiol in some forms of CAIS.

- A previously unreported AR mutation - p.Glu2_Met190del (c.2T>C) - is found in a CAIS patient and results in blunted AR transcriptional activity under testosterone treatment.

\section{Background}

Complete androgen-insensitivity syndrome (CAIS) is a disorder of sex development (46,XY DSD) in which patients exhibit external female genitalia and normal breast development but have a blind vagina, an absent uterus and female adnexa, and abdominal or inguinal testes. CAIS is a disorder characterized by a resistance to androgens and caused primarily by mutations in the androgen receptor $(A R)$ or its co-activators (1). The diagnosis of CAIS can be made during the neonatal period when there is a discordant phenotype-karyotype, during childhood with the discovery of inguinal hernia, and/or during adolescence in the setting of primary amenorrhea.

Gonadectomy has been performed in CAIS to alleviate the risk of gonadal germ cell cancer (GGCC) (2). As GGCC appears to occur mainly after puberty, gonadectomy is usually delayed to allow for spontaneous and complete 
breast development (3). Given the paucity of data on the true frequency of GGCC $(2,4,5,6)$ some women with CAIS opt to decline surgery.

In CAIS, breasts develop normally due to a high concentration of serum testosterone (T) that is naturally aromatized to estradiol. However, when gonadectomy is performed prior to puberty, secondary sexual characteristics are induced by exogenous estradiol treatment.

Herein, we report the case of a young woman with CAIS carrying a novel loss-of-function $A R$ mutation who exhibited severe lack of libido after gonadectomy performed at age 26 .

\section{Case presentation}

At age 16, the patient presented with primary amenorrhea and external female genitalia. Her family history was unremarkable except for an unmarried maternal aunt without children who was not contacted, as per the patient's request. The patient was diagnosed with CAIS based on 46,XY karyotype, a short pouch vagina, an absence of Müllerian structures on ultrasound, and a markedly increased serum testosterone (T) concentration. Laparoscopy to identify gonads was unsuccessful, and the patient was placed on oral estradiol therapy and had routine clinical and psychological follow-ups for the next 3 years. Thereafter, the patient was lost to follow-up. At age 26 , the patient experienced a growing concern regarding an increased risk of gonadoblastoma and sought evaluation by a surgeon. Pelvic MRI revealed intra-abdominal gonads and an absence of Müllerian structures.

\section{Investigation}

The patient's serum $\mathrm{T}$ concentration was $8 \mathrm{nmol} / \mathrm{L}$, suggestive of CAIS. She underwent a successful bilateral gonadectomy, and the gonads measured $6.5 \times 3 \times 2 \mathrm{~cm}$ and $5.5 \times 3 \times 2.5 \mathrm{~cm}$, respectively. Histological analysis by the hospital pathology department revealed no signs of neoplasia. Consistent with CAIS, histology revealed feminized testes with immature seminiferous tubules lined by cylindrical Sertoli cells with clear cytoplasm, and absent Leydig and germ cells (Fig. 1A, with normal testicular morphology shown in 1B) (post-surgery, serum $\mathrm{T}$ was $0.4 \mathrm{nmol} / \mathrm{L}$, consistent with bilateral gonadectomy. Oral estradiol therapy was reinitiated at $2 \mathrm{mg}$ daily.

\section{Treatment}

She next consulted our endocrine clinic at age 30 . Despite a successful relationship with her husband, she described a rapid decrease in libido 6 months following the gonadectomy despite reported compliance with the estradiol treatment. We hypothesized that low serum $\mathrm{T}$ concentration following gonadectomy could be the cause of her loss of libido. The patient agreed to discontinue oral estradiol treatment for 1 month. During the washout period with no treatment, the patient's FSFI (Female Sexual Function Index (7)) was below normal, with low scores for sexual function (i.e. desire, arousal, orgasm, and satisfaction noted) (Table 1 and Supplementary data, see section on supplementary materials given at the end of this article). After 2 months on testosterone gel therapy (Testogel ${ }^{\circ} 50 \mathrm{mg}$ daily), her libido increased and her repeated FSFI showed normalization of all individual categories (Table 1).

\section{Outcome and follow-up}

Despite the patient's desire to remain on testosterone, treatment was discontinued after 6 months due to medical insurance issues. Two weeks later, hormone replacement therapy was reinitiated (Estradiol $2 \mathrm{mg}$ daily (Estrofem ${ }^{\circ}$ )) resulting in a progressive loss of libido, as confirmed by a low composite FSFI 1 month after the reinitiation of estradiol (Table 1). A SF-36 quality of life questionnaire was performed and did not show any changes across the different hormonal regimens except for emotional well-being and energy (see Supplementary Table 1). The effectiveness of $\mathrm{T}$ treatment on both libido and well-being prompted us to further investigate, at the molecular level, a potential residual activity of the androgen receptor in this patient.

\section{Genetic testing and molecular characterization of AR MRNA}

After informed consent, the patient's DNA was extracted from peripheral blood leukocytes using the PureGene kit (Qiagen), and RNA was extracted from whole blood using the PAXgene Blood RNA Kit (PreAnalytiX) with RT performed using M-MLV RT (Invitrogen $^{\text {TM }}$ ). The eight genomic exons and the cDNA of the AR gene (GenBank reference NM_000044) were Sanger sequenced in both directions according to standard methods (see Supplementary) to confirm potential mutations and exclude splicing defects.

A mutation was identified in the start methionine, p.Glu2_Met190del (c.2T>C) (Fig. 1C), which was absent in the $>140000$ controls of the gnomAD database (http:// gnomad.broadinstitute.org/). This mutation has not been 


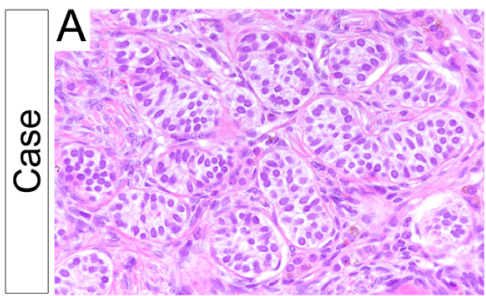

C
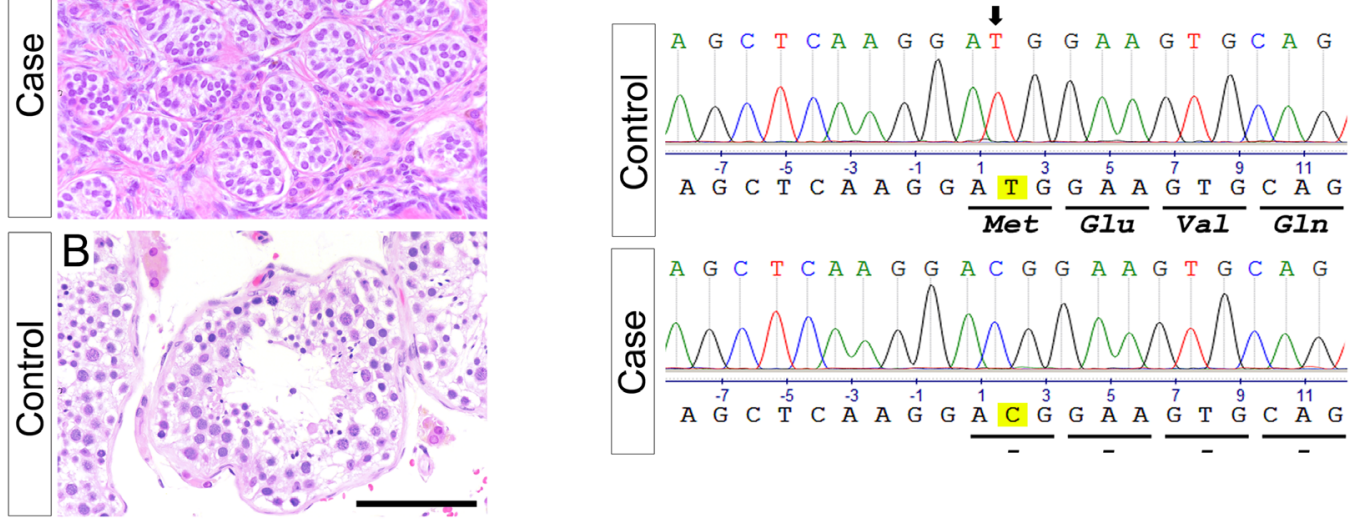

D

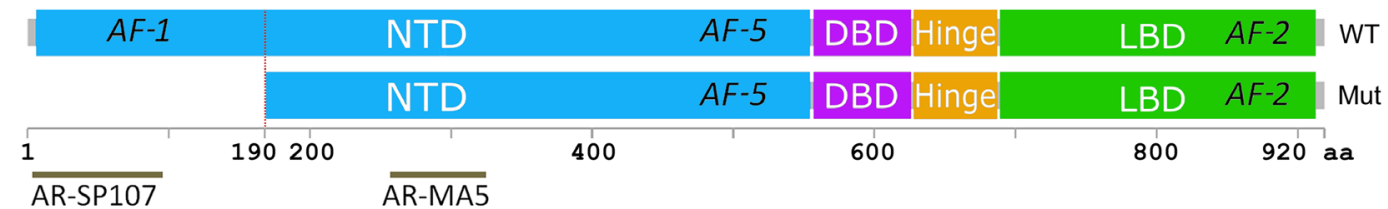
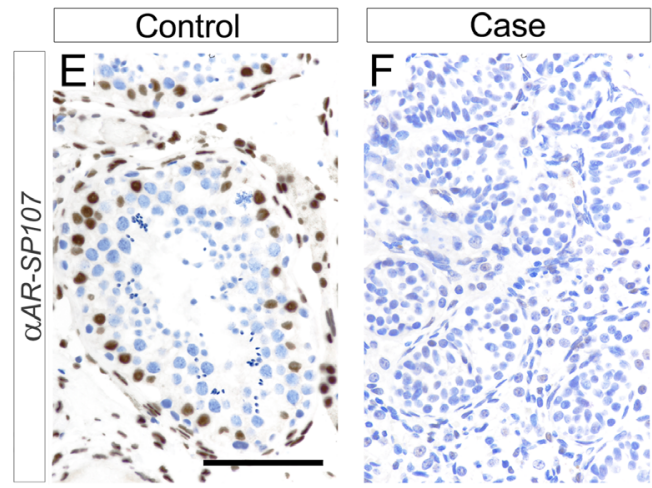

I

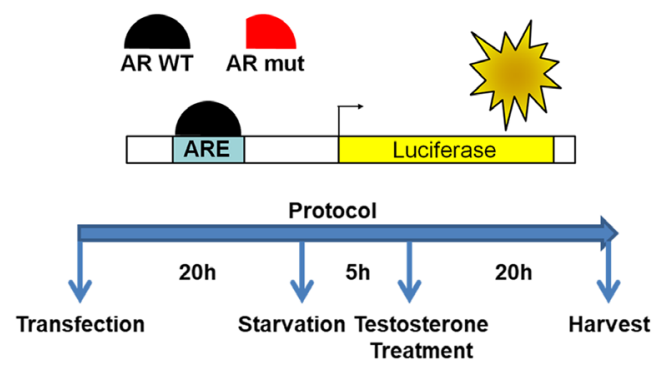

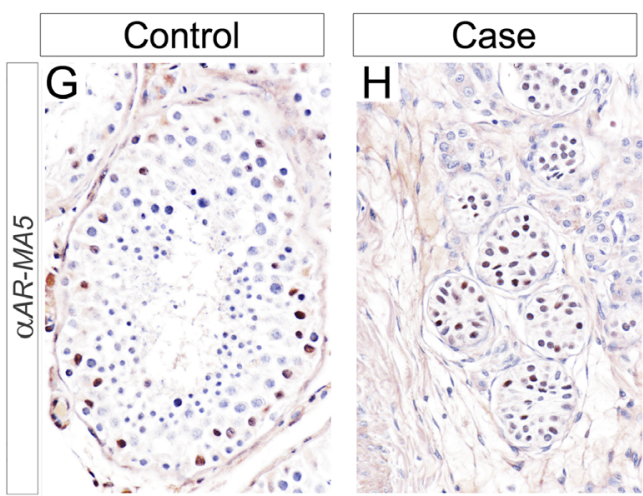

$\mathrm{J}$

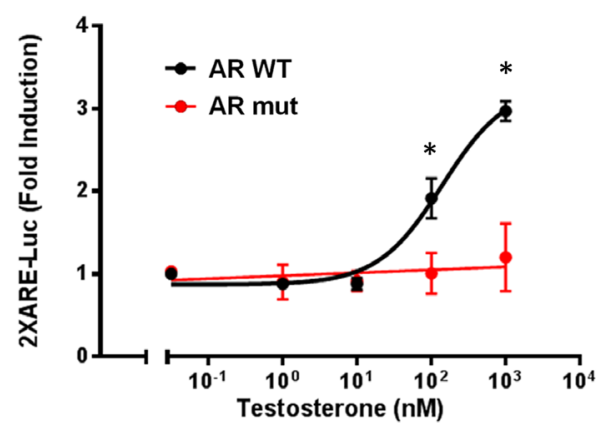

Figure 1

Identification and molecular characterization of c.2T>C AR mutation. (A and B) Representative hematoxylin-eosin-stained sections (H\&E-stain) from control and patient testes. (C) Representative chromatograms showing the loss of the canonical translation start codon in patient DNA vs control. (D) Schematic of human WT and mutant AR proteins illustrating structural domains, regions and the targeted regions of specific anti-AR antibodies. NTD, $\mathrm{N}$-terminal domain; DBD, DNA binding domain; Hinge, hinge domain; LBD, ligand-binding domain; AF-1, activation function 1 region; AF-2, activation function 2; AF-5, activation function 5. (E, F, G and H) Immunohistochemistry of patient testis. (E, F) Representative sections of control and patient testes after AR immunohistochemistry using antibodies specifically targeting the full length AR or $(G, H)$ recognizing both WT and the truncated AR. Scale bars: $50 \mu \mathrm{m}$. (I) Molecular assay principle and protocol for cells (COS-7) treatment. () Results of the testosterone response of transfected cells with either WT or mutated human AR. Data represent the average \pm S.E.M. of three independent experiments. Data have been analyzed by two-way ANOVA followed by Bonferroni correction; $* P<0.0001$. 
Table 1 Comparison of hormonal values and FSFI score at baseline, with T treatment only and E treatment only.

\begin{tabular}{|c|c|c|c|c|}
\hline & $\begin{array}{l}\text { Gonadectomy } \\
\text { no treatment }\end{array}$ & $\begin{array}{c}\text { Testosterone alone } \\
(50 \mathrm{mg} / \mathrm{day})\end{array}$ & $\begin{array}{c}\text { Estradiol } \\
\text { alone }(2 \mathrm{mg} / \text { day })\end{array}$ & $\begin{array}{l}\text { Normal } \\
\text { range }\end{array}$ \\
\hline \multicolumn{5}{|l|}{ Hormonal values } \\
\hline Testosterone (nmol/L) & 0.9 & 24.1 & 1.1 & $<2$ \\
\hline Estradiol (nmol/L) & 0.4 & 0.1 & 0.33 & $0.13-0.31$ \\
\hline \multicolumn{5}{|c|}{ Female Sexual Function Index (FSFI) questionnaire } \\
\hline Total score & 19.1 & 34.5 & $\underline{22}$ & $\geq 23$ \\
\hline Desire & $\underline{0.6}$ & 4.8 & $\underline{2.4}$ & $\geq 3.9$ \\
\hline Arousal & $\underline{2.1}$ & 5.7 & $\underline{3}$ & $\geq 3.9$ \\
\hline Orgasm & $\underline{2}$ & 6 & 1.6 & $\geq 3.9$ \\
\hline Satisfaction & 2.4 & 6 & $\underline{3.6}$ & $\geq 3.9$ \\
\hline Lubrication & 6 & 6 & 5.4 & $\geq 3.9$ \\
\hline Pain & 6 & 6 & 6 & $\geq 3.9$ \\
\hline
\end{tabular}

In bold are the values of the FSFI total score. Underlined values are outside the reference intervals.

previously reported in patients with CAIS (Androgen Receptor Database (http://androgendb.mcgill.ca/)), and literature search), and cDNA sequencing revealed no defects in splicing. The mutant AR was predicted to utilize the next in-frame methionine codon as a start, resulting in a truncated protein missing the first 190 amino acids. This putative deletion encompasses regions essential for the transcriptional activity of AR, including the activation function 1 (AF-1) region (7) (Fig. 1D).

\section{Histology and immunohistochemistry}

As testicular tissue was available from the patient's gonadectomy, informed consent was obtained to evaluate the expression of mutant AR protein in the testis. Testicular tissues from the patient and a healthy subject were formalin-fixed and paraffin-embedded. Immunohistochemical analysis for the expression of AR was performed using the rabbit monoclonal anti-AR antibody (SP107, Cell Marque, Rocklin, CA, USA) and the mouse monoclonal anti-AR antibody (clone AR441, ThermoFisher Scientific) (see Supplementary for specific conditions). These antibodies against the AR protein were selected to target the N-terminal portion of WT AR (AR-SP107) that is part of the putative deletion in the mutant AR protein, and a more distal epitope (ARMA5) retained in the predicted truncated protein (Fig. 1D). Control testicular tissue showed robust staining for both AR-SP107 and AR-MA5 (Fig. 1E and G). As expected, immunoreactivity for the AR-SP107 was absent in the patient's testicular tissue (Fig. 1F), while the downstream AR-MA5 antibody showed positive staining in Sertoli cell nuclei (Fig. 1H) consistent with the expression of a truncated AR receptor.

\section{In vitro assays}

We assessed both WT and mutant AR functionality for their ability to activate a consensus androgen response element (ARE) upon testosterone priming using a luciferase reporter assay as previously published (8) (Fig. 1I) with only minor modifications (as described in the Supplementary data). In contrast to the WT protein, the mutant AR did not show any activity when treated with increasing doses of testosterone, consistent with a total loss of function of the N-terminal truncated protein (Fig. 1J).

\section{Discussion}

We report the case of a CAIS patient who underwent gonadectomy at age 26 with a subsequent low libido which was successfully treated by testosterone but not by estradiol. The literature is sparse and inconclusive regarding which hormone replacement therapy is the most effective in CAIS to increase libido post-gonadectomy. A recent randomized crossover trial in 26 CAIS patients compared the effectiveness of testosterone vs estradiol for quality of life and sexual desire (9). Although both sex steroid replacement therapies were ineffective in recovering the decreased psychological well-being, they did lead to an improvement in sexual function. In particular, testosterone was superior to estradiol treatment for increasing sexual desire without additional side effects, indicating that testosterone therapy appears to be an alternative treatment for decreased libido in women with CAIS.

The mode of action by which testosterone improves sexual desire is still largely unknown. Notably, our patient has an N-terminal truncated AR lacking the AF-1 domain critical for transcriptional activity, consistent 
with an absent response to testosterone in vitro. However, testosterone therapy led to a robust increase in sexual function, which is inconsistent with a genomic action of testosterone.

It is possible that a non-genomic action of androgens resulted in the increased libido in our patient with a total loss-of-function $A R$ mutation. Non-genomic actions of steroid hormones such as progesterone and estradiol have been well demonstrated $(10,11)$, while the evidence of a membrane androgen receptor is growing (12). However, additional functional studies are needed to specifically implicate these receptors in the non-genomic actions of androgen in human physiology.

Alternatively, the aromatization of testosterone to estradiol may be important in stimulating sexual desire in females. However, we observed no significant improvement of libido in our patient after oral estradiol treatment, consistent with the Birnbaum study (9). It is, therefore, possible that testosterone could undergo a central aromatization to estradiol in order to shape and locally activate sexual behavior circuits within the brain $(13,14)$. Indeed, a recent study in monkeys demonstrated that local and rapid neuroestrogenic pathways are required for a full GnRH and LH surge and cannot be compensated by peripheral estrogen $(15,16)$. Recent clinical studies based on pharmacologically induced hypogonadism in healthy volunteers reported a profound decrease in sexual functioning in both women and men. In this context, estradiol and/or progesterone were unable to restore sexual function in females (17), while testosterone treatment restored normal libido in men. Further, testosterone therapy with aromatase inhibitor led to decreased libido in men (18).

Combined, these results suggest the involvement of central aromatization of testosterone to estradiol in libido. In addition, placebo-controlled and meta-analysis studies confirmed the beneficial effect of testosterone on sexual desire and function in females $(19,20,21)$. Further studies evaluating the response to testosterone therapy in the presence of an aromatase inhibitor will help clarify the direct effect of testosterone and/or its aromatization to estradiol in stimulating sexual desire in females.

In addition, the presence of a $\mathrm{Y}$ chromosome in CAIS patients lacking androgen action may contribute to differences in neuronal networks involved in sexual desire. However, several neuroimaging studies have shown that CAIS patients have feminized brains $((22,23,24)$, although some masculine features have been observed (25) consistent with a direct effect of Y chromosome genes. Thus, CAIS women may depend more on the central aromatization of testosterone to estradiol than non-CAIS women.

This unique case of CAIS suggests that testosterone therapy may be more effective than estradiol in restoring sexual desire after gonadectomy, either through central aromatization or non-genomic actions. Further doubleblinded, placebo-controlled studies are required to assess the risks and benefits of long-term testosterone therapy in these patients.

\section{Supplementary materials}

This is linked to the online version of the paper at https://doi.org/10.1530/ EDM-21-0031.

\section{Declaration of interest}

The authors declare that there is no conflict of interest that could be perceived as prejudicing the impartiality of the research reported.

\section{Funding}

This research did not receive any specific grants from any funding agency in the public, commercial or not-for-profit sector.

\section{Patient consent}

A written consent was obtained to publish clinical information of the patient reported here.

\section{Author contribution statement}

L M, F P H and N P followed the patient and interpreted the clinical data; S L $\mathrm{R}$ and $\mathrm{A} M$ provided the histological examinations; $\mathrm{A} M$ and $\mathrm{N} N$ performed in vitro experiments, analysis and designed the figures; J A and A M performed the genetic analysis and the molecular characterization of AR mRNA; $F$ S aided in interpreting the results and worked on the manuscript; $L M, A M, J A, N N$ and N P drafted the manuscript. All authors discussed the results and commented on the manuscript. All authors read and approved the final manuscript.

\section{Acknowledgements}

The authors thank the family and collaborators for their participation in this study.

\section{References}

1 Adachi M, Takayanagi R, Tomura A, Imasaki K, Kato S, Goto K, Yanase T, Ikuyama S \& Nawata H Androgen-insensitivity syndrome as a possible coactivator disease. New England Journal of Medicine 2000 343 856-862. (https://doi.org/10.1056/NEJM200009213431205)

2 Wunsch L, Holterhus PM, Wessel L \& Hiort O Patients with disorders of sex development (DSD) at risk of gonadal tumour development: 
management based on laparoscopic biopsy and molecular diagnosis. BJU International 2012110 E958-E965. (https://doi.org/10.1111/j.1464410X.2012.11181.x)

3 Hughes IA, Davies JD, Bunch TI, Pasterski V, Mastroyannopoulou K \& MacDougall J. Androgen insensitivity syndrome Lancet 2012380 1419-1428. (https://doi.org/10.1016/S0140-6736(12)60071-3)

4 Tack LJW, Maris E, Looijenga LHJ, Hannema SE, Audi L, Kohler B, Holterhus PM, Riedl S, Wisniewski A, Flück CE, et al. Management of gonads in adults with androgen insensitivity: an international survey. Hormone Research in Paediatrics 201890 236-246. (https://doi. org/10.1159/000493645)

5 Hannema SE, Scott IS, Rajpert-De Meyts E, Skakkebaek NE, Coleman N \& Hughes IA Testicular development in the complete androgen insensitivity syndrome. Journal of Pathology 2006208 518-527. (https://doi.org/10.1002/path.1890)

6 Kaprova-Pleskacova J, Stoop H, Bruggenwirth H, Cools M, Wolffenbuttel KP, Drop SL, Snajderova M, Lebl J, Oosterhuis JW \& Looijenga LH Complete androgen insensitivity syndrome: factors influencing gonadal histology including germ cell pathology. Modern Pathology 201427 721-730. (https://doi.org/10.1038/ modpathol.2013.193)

7 Bevan CL, Hoare S, Claessens F, Heery DM \& Parker MG The AF1 and AF2 domains of the androgen receptor interact with distinct regions of SRC1. Molecular and Cellular Biology 199919 8383-8392. (https://doi. org/10.1128/mcb.19.12.8383)

8 Pitteloud N, Villegas J, Dwyer AA, Crowley WF, Jr, McPhaul MJ \& Hayes FJ Acute stress masking the biochemical phenotype of partial androgen insensitivity syndrome in a patient with a novel mutation in the androgen receptor. Journal of Clinical Endocrinology and Metabolism 200489 1053-1058. (https://doi.org/10.1210/jc.2003-031373)

9 Birnbaum W, Marshall L, Werner R, Kulle A, Holterhus PM, Rall K, Köhler B, Richter-Unruh A, Hartmann MF, Wudy SA, et al. Oestrogen versus androgen in hormone-replacement therapy for complete androgen insensitivity syndrome: a multicentre, randomised, double-dummy, double-blind crossover trial. Lancet: Diabetes and Endocrinology 20186 771-780. (https://doi.org/10.1016/S22138587(18)30197-9)

10 Singh M, Su C \& Ng S Non-genomic mechanisms of progesterone action in the brain. Frontiers in Neuroscience 20137 159. (https://doi. org/10.3389/fnins.2013.00159)

11 Cato AC, Nestl A \& Mink S Rapid actions of steroid receptors in cellular signaling pathways. Science's STKE: Signal Transduction Knowledge Environment 20022002 re9. (https://doi.org/10.1126/stke.2002.138. re9)

12 Foradori CD, Weiser MJ \& Handa RJ Non-genomic actions of androgens. Frontiers in Neuroendocrinology 200829 169-181. (https:// doi.org/10.1016/j.yfrne.2007.10.005)

13 Christensen LW \& Clemens LG Intrahypothalamic implants of testosterone or estradiol and resumption of masculine sexual behavior in long-term castrated male rats. Endocrinology 197495 984-990. (https://doi.org/10.1210/endo-95-4-984)

14 Bakker J, Honda S, Harada N \& Balthazart J The aromatase knockout mouse provides new evidence that estradiol is required during development in the female for the expression of sociosexual behaviors in adulthood. Journal of Neuroscience 200222 9104-9112. (https://doi. org/10.1523/JNEUROSCI.22-20-09104.2002)

15 Kenealy BP, Keen KL, Garcia JP, Kohlenberg LK \& Terasawa E Obligatory role of hypothalamic neuroestradiol during the estrogen-induced LH surge in female ovariectomized rhesus monkeys. PNAS 2017114 13804-13809. (https://doi.org/10.1073/pnas.1716097115)

16 Terasawa E \& Kenealy BP Neuroestrogen, rapid action of estradiol, and GnRH neurons. Frontiers in Neuroendocrinology 201233 364-375. (https://doi.org/10.1016/j.yfrne.2012.08.001)

17 Schmidt PJ, Steinberg EM, Negro PP, Haq N, Gibson C \& Rubinow DR Pharmacologically induced hypogonadism and sexual function in healthy young women and men. Neuropsychopharmacology 200934 565-576. (https://doi.org/10.1038/npp.2008.24)

18 Finkelstein JS, Lee H, Burnett-Bowie SA, Pallais JC, Yu EW, Borges LF, Jones BF, Barry CV, Wulczyn KE, Thomas BJ, et al. Gonadal steroids and body composition, strength, and sexual function in men. New England Journal of Medicine 2013369 1011-1022. (https://doi.org/10.1056/ NEJMoa1206168)

19 Somboonporn W, Davis S, Seif MW \& Bell R Testosterone for peri- and postmenopausal women. Cochrane Database of Systematic Reviews 2005 4 CD004509. (https://doi.org/10.1002/14651858.CD004509.pub2)

20 Elraiyah T, Sonbol MB, Wang Z, Khairalseed T, Asi N, Undavalli C, Nabhan M, Firwana B, Altayar O, Prokop L, et al. Clinical review: the benefits and harms of systemic testosterone therapy in postmenopausal women with normal adrenal function: a systematic review and meta-analysis. Journal of Clinical Endocrinology and Metabolism 201499 3543-3550. (https://doi.org/10.1210/jc.20142262)

21 Davis SR, Moreau M, Kroll R, Bouchard C, Panay N, Gass M, Braunstein GD, Hirschberg AL, Rodenberg C, Pack S, et al. Testosterone for low libido in postmenopausal women not taking estrogen. New England Journal of Medicine 2008359 2005-2017. (https://doi. org/10.1056/NEJMoa0707302)

22 Hamann S, Stevens J, Vick JH, Bryk K, Quigley CA, Berenbaum SA \& Wallen $\mathrm{K}$ Brain responses to sexual images in $46, \mathrm{XY}$ women with complete androgen insensitivity syndrome are female-typical. Hormones and Behavior 201466 724-730. (https://doi.org/10.1016/j. yhbeh.2014.09.013)

23 van Hemmen J, Saris IMJ, Cohen-Kettenis PT, Veltman DJ, Pouwels PJW \& Bakker J Sex differences in white matter microstructure in the human brain predominantly reflect differences in sex hormone exposure. Cerebral Cortex 201727 2994-3001. (https://doi.org/10.1093/ cercor/bhw156)

24 van Hemmen J, Veltman DJ, Hoekzema E, Cohen-Kettenis PT, Dessens AB \& Bakker J Neural activation during mental rotation in complete androgen insensitivity syndrome: the influence of sex hormones and sex chromosomes. Cerebral Cortex 201626 1036-1045. (https://doi.org/10.1093/cercor/bhu280)

25 Savic I, Frisen L, Manzouri A, Nordenstrom A \& Linden Hirschberg A Role of testosterone and Y chromosome genes for the masculinization of the human brain. Human Brain Mapping 201738 1801-1814. (https://doi.org/10.1002/hbm.23483)

Received in final form 20 April 2021

Accepted 13 May 2021 